\title{
A Tool Selection Framework for Cross Platform Mobile App Development
}

\author{
Felix Appiah \\ PG Student, Department \\ Of Computer Science \\ Kwame Nkrumah \\ University of Science and \\ Technology, Kumasi, \\ Ghana
}

\author{
J. B. Hayfron-Acquah \\ $\mathrm{PhD}$ \\ Department Of Computer \\ Science \\ Kwame Nkrumah \\ University of Science and \\ Technology, Kumasi,
}

Ghana

\author{
Joseph K. Panford \\ Department Of Computer \\ Science \\ Kwame Nkrumah \\ University of Science and \\ Technology, Kumasi, \\ Ghana
}

\author{
Frimpong Twum \\ Department Of Computer \\ Science \\ Kwame Nkrumah \\ University of Science and \\ Technology, Kumasi, \\ Ghana
}

\begin{abstract}
Cross platform Mobile application development is currently enjoying some good riddance in the Mobile App Development Community. Nonetheless, developers are somehow confronted with a tool selection dilemma since development for multiple platforms are still at the inceptive stage. In this paper we propose a framework for choosing the appropriate Cross Platform Development Tool for a given project. The framework defines the set of criteria to be considered for evaluation and makes pair-wise comparison to compute the priority for the criteria as well as priority of the alternative tools compared. The implementation of the framework on the Tools: PhoneGap, Titanium and Xamarin recommend PhoneGap as the preferred tool for Cross Platform Development. The result from the implementation also considers the capability criteria as the most important in Mobile Cross Platform Development.
\end{abstract}

\section{General Terms}

Cross Platform Mobile Application Development.

\section{Keywords}

Tool Selection Framework, Mobile App development, Cross Platform Tools

\section{INTRODUCTION}

The popularity of mobile devices has motivated majority of vendors to get on board and contribute to the provision of mobile operating systems as well as software that run on mobile devices [1]. Different vendors have developed their own proprietary method of developing applications for their devices using a variety of programming languages and Development Kits. This means that an application developed for Google's Android operating system will not run on the RIMS blackberry platform. This had led to a challenge in the mobile computing industry known as platform fragmentation. The issue of fragmentation becomes more challenging for developers when applications built for a targeted platform are not able to run on different versions of hardware devices [2].

This makes cross platform development very relevant and inevitable. A survey by Appcelerator and IDC in August 2012 showed that companies continue to be very interested in cross platforms regardless of the challenges and difficulties [3]. In 2011, developers had shown interest in running on twice as many platforms as a similar survey in the previous year had indicated a multi-platform patronage by developers averaging an incredible four operating systems [4]. This trend continued to increase in 2012 [3].
Despite the popularity and potential for developing for multiple platforms, there is no detailed metric to measure the capability and performance of Cross Platform Development Tools (herein after referred to as CPDTs). Through the development an evaluation framework based on acceptable metrics for CPDTs, developers will gain the knowledge needed to determine which tool to use for their application.

\section{RELATED WORKS}

[15] provided a comparison for four Cross Platform Tools. All these tools were viewed in respect to their ability to deliver animation applications. Titanium according to [15] emerged as the best tool for developing animation applications. The work of [15] lacked the needed depth to allow for its consideration in business applications due to the fact that, only one criterion was considered. The tools compared included: PhoneGap, JQuery, Titanium and MoSnyc.

[5][6] in their works also compared features of CPDTs although their comparison lacked greater depth. Comparison of tool features was done with a 13-item chart [5]. Storage and camera access among other important features were covered in the survey. However, the reports did not include performance evaluation and discussion of development practices.

Many CPDTs are discussed in [7] but just partial comparison was provided. They compared native and web-based user interface elements as well as the importance of well performing applications. However, the authors emphasized that they were not concerned with the internal workings of the tools but rather the approval of the application for mobile stores. [7] further discusses the lack of debugging tools in many CPDTs in the system currently and provided an 8-point scale to compare features. The authors developed a simple application that provides a screen with a text label and measured the start time and the RAM usage for nine CPDTs.

Currently, the PCMark suite is the most prominent desktop PC benchmarking software and uses several open source and commercial applications [8]. Using the contained test suites allow CPU, memory, graphics and hard disk performance analysis. There had not been any equivalent gold standard among these test suites in the mobile community [10], although work is in progress on native benchmarks for different platforms. Some currently available benchmarks are Quadrant proposed in Aurora [11] and [9]. Published work on mobile benchmarking is very limited. Performing a simple test on Android has been the basis for some time now in terms comparing CPDTs [15]. 


\section{PROPOSED FRAMEWORK}

The proposed framework can be divided into four stages: Problem Definition, Ranking Criteria, Ranking of Alternatives and Evaluation Report as shown in Figure 3.

\subsection{Problem Definition (Level 1)}

A decision is a result of a comparison of one or more alternatives with respect to one or more criteria that is considered relevant for the decision [14]. Among these relevant criteria, some are considered more and some as less important, a process that involves assigning weights to the criteria according to their relative importance. For the majority of our everyday decisions which usually have an impact only on us and our immediate future, weights are assigned intuitively based on relevant decision criteria.

\subsection{Ranking of Criteria (Level 2)}

In arriving at the criterion to be included in the framework, relevant data had to be collected from varied sources including primary and secondary sources. The sources including documentation from tool vendors as well as experts in the field of software development helped to gather relevant facts to arrive at the appropriate criteria to include in the framework. Procedures embarked upon to obtain the primary data included focus group discussions and interviews with 6(Six) software developers with more than 10 years of experience in the industry. The criteria considered for the evaluation includes: Capabilities, Performance, Development Speed, Native UI, Learning Curve and Device Access. The relative preference among the various criteria is measured by comparing individual factors against each other in a pairwise comparison matrix. Numerical values expressing a judgement of the relative importance (or preference) of one factor against another has to be assigned to each factor. A comparison scale suggested by [14] is used to make comparison between factors (criteria). The scale for comparison consists of values ranging from 1 to 9 which describe the intensity of importance, whereby a value of 1 expresses "equal importance" and a value of 9 is given to those factors having an "extreme importance" over another factor as shown in table 1 . The scale shown in Table 1 indicates how many times an alternative is more relevant than another one, with respect to a specific criterion. The relevance is established according to either subjective or objective statements. A matrix at this stage will collect the pairwise comparison of the criteria by the decision maker as illustrated in Table 2 .

A relative verbal appraisal between pairs, similar to what happens in daily conversations is adequate on the part of decision makers during comparison. To check for consistency of the pair-wise comparison, a consistency ratio $\mathrm{cr}=\frac{\mathrm{ci}}{\mathrm{ri}}$ where $\mathrm{ci}=$ consistency index and $\mathrm{ri}=$ random index has to be computed. The Consistency Index should be less than 0.1 . Consistency ratio less than 1.0 means responds are not consistent. The consistency index (ci) is calculated using the formula $\mathrm{ci}=\frac{\text { lamdamax }-\mathrm{n}}{\mathrm{n}-1}$ where $\mathrm{n}$ is equal to the number of criteria compared and lamdamax is the highest product of sum of each criteria column and the priority of the criteria.

\subsection{Ranking of Alternatives (Level 3)}

The priority which indicates the ranking of the alternatives with respect to a given criteria is evaluated. The priority is computed by finding the 6th root of the product of each row in the matrix and dividing the resultant of each by the total. Finally the weighted average rating of each decision alternative is achieved by multiplying the criteria weights from level 2 by the rating of the decision alternatives of each criteria and finally summing up the respective products

\subsection{Evaluation Report}

The results of the individual matrices are interpreted and rankings of the compared platforms made based on the criteria selected. The platform with the highest standardized weight gets the nod as the ideal platform for cross platform development. .

\section{IMPLEMENTATION}

In order to implement the framework proposed, three (3) Mobile Cross platform tools are used namely: PhoneGap, Titanium and Xamarin. These tools are compared and ranked based on the criteria outlined in section 3 .

\subsection{Problem Definition: (Level 1)}

Although the framework can compare any number of tools, three (3) tools namely PhoneGap, Titanium and Xamarin are selected to provide data for the implementation of the framework. These tools are selected based on their popularity and advice from software developers partnered to do the comparison and evaluation.

\section{2. $\quad$ Ranking of Criteria (Level 2)}

A pair-wise comparison is done by capturing the selected criteria in a $6 \times 6$ matrix as illustrated in Table 3 .

\subsubsection{Priority and Lamdamax}

Lamdamax and priority for the 6 criteria are calculated as illustrated by Table 4 . The criteria with the highest priority attracts the highest ranking in it follows in that order.

\subsubsection{Calculation of Consistency Index}

The consistency index (ci) is computed using the formula $\mathrm{ci}=\frac{\text { lamdamax }-\mathrm{n}}{\mathrm{n}-1}$ where $\mathrm{n}=$ number of criteria to be compared. With respect to this problem, the number of criterion is equal to 6 , therefore $\mathrm{n}$ is equal to 6 . Consistency index $=6.325962-6 / 5=0.0651924$.

\subsubsection{Calculation of Consistency Ratio (cr)}

The consistency ratio was arrived at using the formula $\mathrm{cr}=\frac{\mathrm{ci}}{\mathrm{ri}}$ where $\mathrm{cr}=$ consistency ratio, $\mathrm{ci}=$ consistency index and $\mathrm{ri} \stackrel{\mathrm{ri}}{=}$ random index. The rational index is obtained using the rational index table as illustrated in Table 5.From the figures in Table 5, the random index for 6 is 1.24 considering the number of criteria compared which is 6 . Consistency ratio is therefore computed as $c r=\frac{0.0651924}{1.24}=0.052575$. The consistency ratio of 0.052575 is less than 0.1 and indicates that the pairwise comparison made is consistent

\subsection{Ranking of Alternatives (Level 3)}

A pair-wise comparison was done on the three (3) compared alternatives: PhoneGap, Titanium and Xamarin. The priority, lamdamax, ci, ri and cr are computed as shown in Table 6 to Table 11. Table 12 provides the weighted average rating of each of the alternatives.

\subsection{Evaluation Report (Level 4)}

PhoneGap is preferred to Titanium and Xamarin considering the Six (6) criteria which provides the basis for evaluation. In the absence of PhoneGap, Titanium can serve as the alternative since it lies second in the ranking. Detailed report after the implantation is presented in the next section. 


\section{DISCUSSIONS}

By implementing the individual stages in the tool selection framework, each phase of evaluation provides significant information regarding the tools' strengths and weaknesses. These results are presented in this section. The results show the relative importance of each of the criterion and their subsequent ranking derived using the framework.

\subsection{Ranking of Criteria and Tools}

The results in Table 5 illustrate the ranking of criteria. According to the results, the most important criteria with the highest priority is the capability criteria. This means that, during Cross Platform development, developers place much emphasis on the capabilities of the application. Different CPDTs also exhibit strength and weaknesses based a given criteria. The results in Table 6 to Table 11 show the strength and weaknesses of Xamarin, Titanium and PhoneGap. PhoneGap is preferred among the three in terms of its ability to deliver applications with high capabilities. Developing applications with PhoneGap is found to be relatively faster and is the best among the three tools in terms of ease of learning to work with it. These findings are supported by Tables 6,8 and 11. Titanium on the other hand is good for applications which emphasizes on UI appeal and faster access to devices such as camera and accelerometer. These findings are in agreement with that of [2]. Xamarin is considered ideal for UI appeal but falls short in all other criteria.

\subsection{Weighted Average of Tools}

The weighted average for all the tools is computed to determine the best with respect to all the criteria. PhoneGap is considered the best with the highest priority. Titanium comes second with Xamarin assuming the least preferred with the lowest priority. This result is not in agreement with [2] which do not produce an eventual winner after comparison of tools.

\section{CONCLUSION}

The result indicates that, tool selection can have a great impact both negatively and positively on development of a mobile application. Some CPDTs are shown to have performance issues while others provided too little capability. The most attractive part of this framework is that it can be extended to include the addition of new criterion brought by future releases of CPDTs with the core concepts remaining. Future works will focus on extending the framework to include other criteria such as security and user experience.

Table 1: Scale of Comparison (Saaty, 2001)

\begin{tabular}{|c|c|c|}
\hline Intensity & Definition & Explanation \\
\hline 1 & Equally preferred & $\begin{array}{l}\text { Two elements contribute equally to the o the } \\
\text { objective }\end{array}$ \\
\hline 2 & $\begin{array}{l}\text { Between equal and } \\
\text { moderate }\end{array}$ & \\
\hline 3 & $\begin{array}{l}\text { Moderately } \\
\text { preferred }\end{array}$ & One element is slightly more relevant than another \\
\hline 4 & $\begin{array}{l}\text { Between moderate } \\
\text { and strong }\end{array}$ & \\
\hline 5 & Strong & One element is strongly more relevant than another \\
\hline 6 & $\begin{array}{l}\text { Between Strong and } \\
\text { very strong }\end{array}$ & \\
\hline 7 & Very Strong & $\begin{array}{l}\text { One element is very strongly more relevant than } \\
\text { another }\end{array}$ \\
\hline 8 & $\begin{array}{l}\text { Between very strong } \\
\text { and extremely strong }\end{array}$ & \\
\hline 9 & Extreme & One element is extremely more relevant than another \\
\hline
\end{tabular}

Table 2: Pairwise Comparison Matrix for the Criteria

\begin{tabular}{|l|l|l|l|l|l|l|}
\hline & Capability & Performance & D.Speed & $\begin{array}{l}\text { Native } \\
\text { UI }\end{array}$ & L.Curve & D.Access \\
\hline Capability & & & & & & \\
\hline Performance & & & & & & \\
\hline D.Speed & & & & & & \\
\hline Native UI & & & & & & \\
\hline L.Curve & & & & & & \\
\hline D.Access & & & & & & \\
\hline
\end{tabular}


Table 3: Pairwise Comparison of Selected Criteria

\begin{tabular}{|l|c|l|l|l|l|l|}
\hline & Capability & Performance & D.Speed & $\begin{array}{l}\text { Native } \\
\text { UI }\end{array}$ & $\begin{array}{l}\text { Learning } \\
\text { Curve }\end{array}$ & $\begin{array}{l}\text { Device } \\
\text { Access }\end{array}$ \\
\hline Capability & 1.00 & 5 & 3 & 7 & 5 & 5 \\
\hline Performance & 0.200 & 1 & 0.5 & 3 & 2 & 2 \\
\hline $\begin{array}{l}\text { Development } \\
\text { Speed }\end{array}$ & 0.333 & 2 & 1 & 4 & 3 & 2 \\
\hline Native UI & 0.143 & 0.333 & 0.25 & 1 & 0.5 & 0.5 \\
\hline $\begin{array}{l}\text { Learning. } \\
\text { Curve }\end{array}$ & 0.2 & 0.5 & 0.333 & 4 & 1 & 2 \\
\hline Device Access & 0.2 & 0.5 & 0.5 & 2 & 0.5 & 1 \\
\hline
\end{tabular}

Table 4: Calculation of Lamdamax for selected criteria

\begin{tabular}{|c|c|c|c|c|c|c|c|c|c|c|}
\hline & Capabiliti & Performance & Dev Speed & Native UI L & L.curve & D.Access & product & 6th root & priority I & lamdamax \\
\hline Capabilities & 1.00 & 5 & 3 & 7 & 5 & 5 & 2625 & 3.714111 & 0.457376 & 6.325962 \\
\hline Performance & 0.200 & 1 & 0.5 & 3 & 2 & 2 & 1.2 & 1.030853 & 0.126945 & \\
\hline Dev.Speed & 0.333 & 2 & 1 & 4 & 3 & 2 & 15.984 & 1.587136 & 0.195449 & \\
\hline Native UI & 0.143 & 0.333 & 0.25 & 1 & 0.5 & 0.5 & 0.002976 & 0.379266 & 0.046705 & \\
\hline L.curve & 0.2 & 0.5 & 0.333 & 4 & 1 & 2 & 0.2664 & 0.80215 & 0.098781 & \\
\hline D.Access & 0.2 & 0.5 & 0.5 & 2 & 0.5 & 1 & 0.05 & 0.606962 & 0.074745 & \\
\hline sum & 2.08 & 9.33 & 5.58 & 21.00 & 12.00 & 12.50 & & 8.120479 & 1.00 & \\
\hline sum*priority & 0.949512 & 1.184776707 & 1.091189655 & 0.980801 & 1.185374 & 0.934308 & 6.325962 & & & \\
\hline
\end{tabular}

Table 5: Table of Random Index (ri)

\begin{tabular}{|l|l|l|l|l|l|l|l|l|}
\hline $\mathrm{n}$ & 1 & 2 & 3 & 4 & 5 & 6 & 7 & 8 \\
\hline Random Indix (ri) & 0.00 & 0.00 & 0.58 & 0.90 & 0.12 & 1.24 & 1.32 & 1.41 \\
\hline
\end{tabular}

Table 6: Comparison Matrix Based on Capabilities Criteria

\begin{tabular}{|l|l|l|l|l|l|l|l|l|}
\hline Capabilities & PhoneGap & Titanium & Xamarin & priority & Lamdamax & ci & ri & cr \\
\hline PhoneGap & 1.0 & 5.000 & 2.00 & 0.581554 & 3.00366242 & 0.001831 & 0.58 & 0.003157 \\
\hline Titanium & 0.200 & 1 & 0.333 & 0.109449 & & & & \\
\hline Xamarin & 0.5 & 3.000 & 1.000 & 0.308997 & & & & \\
\hline
\end{tabular}

Table 7: Comparison Matrix Based on Performance Criteria

\begin{tabular}{|l|l|l|l|l|l|l|l|l|}
\hline Performance & PhoneGap & Titanium & Xamarin & priority & Lamdamax & ci & ri & cr \\
\hline PhoneGap & 1.0 & 0.20 & 0.33 & 0.109126 & 3.001498763 & 0.000749 & 0.58 & 0.001292 \\
\hline Titanium & 5.000 & 1.00 & 2.0000 & 0.58177 & & & & \\
\hline Xamarin & 3.000 & 0.50 & 1.000 & 0.309109 & & & & \\
\hline
\end{tabular}

Table 8: Comparison Matrix Based on Development Speed Criteria

\begin{tabular}{|l|l|l|l|l|l|l|l|l|}
\hline $\begin{array}{l}\text { Development } \\
\text { Speed }\end{array}$ & PhoneGap & Titanium & Xamarin & priority & Lamdamax & ci & ri & cr \\
\hline PhoneGap & 1.0 & 3.00 & 5.00 & 0.648329 & 3.003694598 & 0.001847 & 0.58000 & 0.003185 \\
\hline Titanium & 0.333 & 1.0 & 2.00 & 0.22965 & & & & \\
\hline Xamarin & 0.200 & 0.50 & 1.00 & 0.122020 & & & & \\
\hline
\end{tabular}

Table 9: Comparison Matrix based on Native UI Criteria

\begin{tabular}{|l|l|l|l|l|l|l|l|l|}
\hline Native UI & PhoneGap & Titanium & Xamarin & priority & Lamdamax & ci & ri & cr \\
\hline PhoneGap & 1.000 & 0.17 & 0.25 & 0.88983 & 3.009202713 & 0.004601 & 0.5800 & 0.007933 \\
\hline Titanium & 6.00 & 1.00 & 2.000 & 0.58763 & & & & \\
\hline Xamarin & 4.00 & 0.50 & 1.000 & 0.323386 & & & & \\
\hline
\end{tabular}


Table 10: Comparison Matrix Based on Device Access Criteria

\begin{tabular}{|l|l|l|l|l|l|l|l|l|}
\hline $\begin{array}{l}\text { Device } \\
\text { Access }\end{array}$ & PhoneGap & Titanium & Xamarin & priority & Lamdamax & ci & ri & cr \\
\hline PhoneGap & 1.00 & 0.17 & 0.33 & 0.095338 & 3.018294707 & 0.009147 & 0.5800 & 0.015771 \\
\hline Titanium & 6.00 & 1.00 & 3.000 & 0.65481 & & & & \\
\hline Xamarin & 3.00 & 0.33 & 1.00 & 0.249856 & & & & \\
\hline
\end{tabular}

Table 11: Comparison Matrix Based on Learning Curve Criteria

\begin{tabular}{|l|l|l|l|l|l|l|l|l|}
\hline $\begin{array}{l}\text { Learning } \\
\text { Curve }\end{array}$ & PhoneGap & Titanium & Xamarin & priority & Lamdamax & ci & ri & cr \\
\hline PhoneGap & 1.00 & 5.00 & 7.00 & 0.739594 & 3.014151882 & 0.007076 & 0.5800 & 0.0122 \\
\hline Titanium & 0.200 & 1.00 & 2.00 & 0.16659 & & & & \\
\hline Xamarin & 0.1429 & 0.50 & 1.00 & 0.093813 & & & & \\
\hline
\end{tabular}

Table 12: Weighted Average rating of each alternative

\begin{tabular}{|l|l|l|l|l|l|l|l|l|}
\hline \multirow{2}{*}{$\begin{array}{c}\text { criteria } \\
\text { Options }\end{array}$} & Capabilities & Performance & $\begin{array}{l}\text { Development } \\
\text { Speed }\end{array}$ & Native UI & L. Curve & D.Access & Score & Ranking \\
\cline { 2 - 9 } \\
\cline { 2 - 9 } PhoneGap & 0.457376 & 0.126945 & 0.195449 & 0.046705 & 0.098781 & 0.074745 & 1.000 & \\
\hline Titanium & 0.885246 & 0.109126 & 0.648329 & 0.088983 & 0.739594 & 0.095338 & 0.629798 & Winner \\
\hline Xamarin & 0.110656 & 0.309109 & 0.12202 & 0.323386 & 0.093813 & 0.249856 & 0.156746 & $3 \mathrm{rd}$ \\
\hline Sum & 1.00 & 1.00 & 1.00 & 1.00 & 1.00 & 1.00 & 1.00 & \\
\hline
\end{tabular}

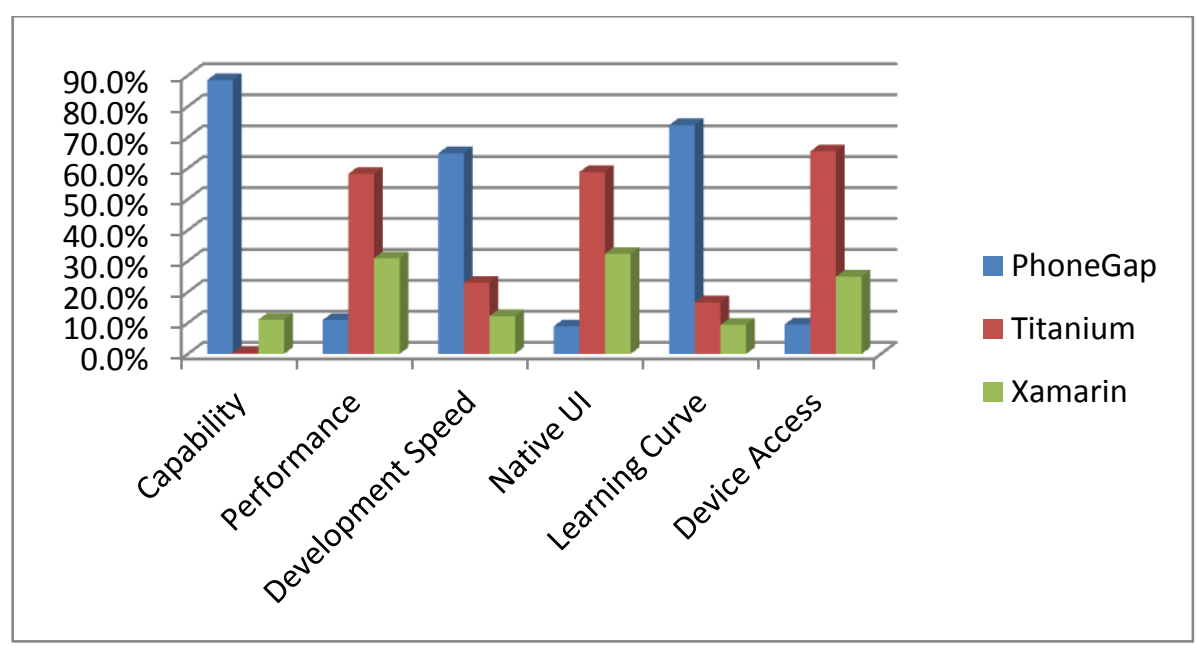

Figure 1: Comparison of CPDTs based on Selected Criteria

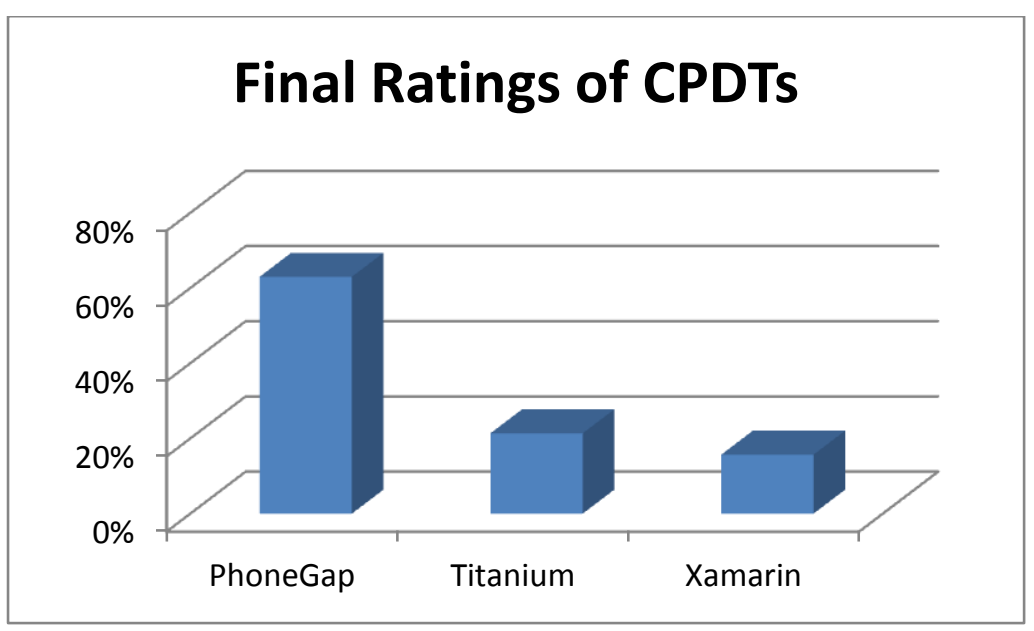

Figure 2: Final Rating of Cross Platform Development Tools 


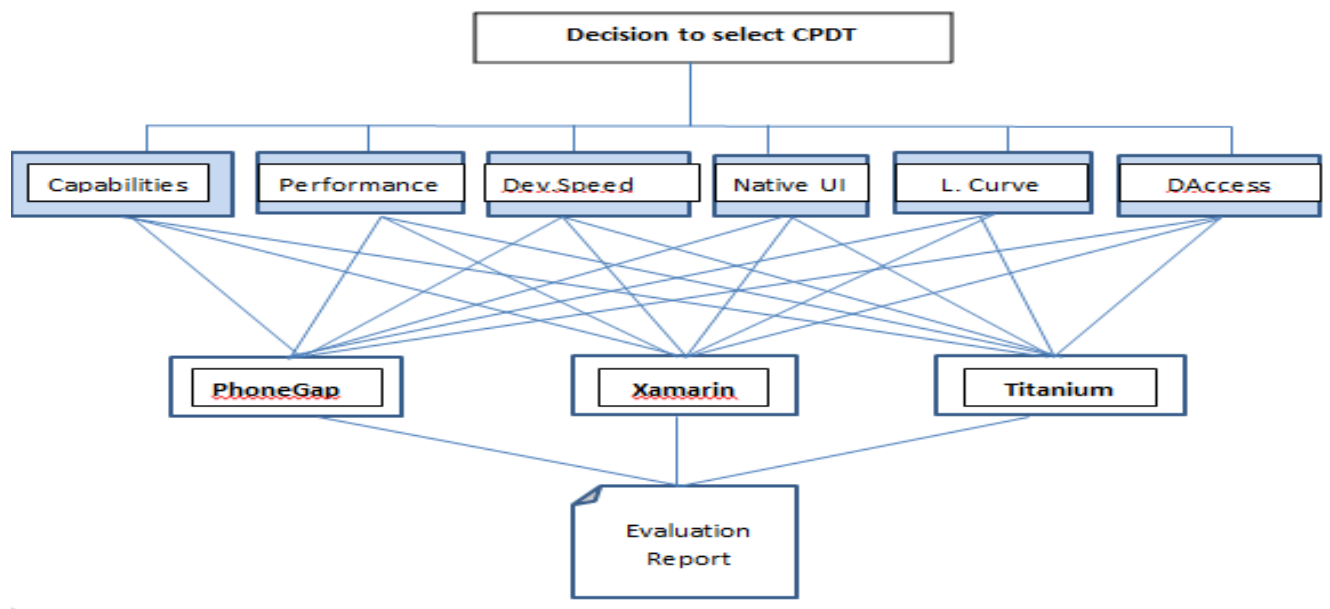

Figure 3: Proposed Framework

\section{REFERENCES}

[1] Pastore, S. (2013) "Mobile operating system and app development strategies": International Conference on Systems, Control and Informatics.

[2] Dhillon, S. (2012) “An Evaluation Framework for cross platform Development". University of Guelph, Ontario Canada.

[3] Appcelerator Inc. 2012 Appcelerator research [Online] Availablefrom: http://www.appcelerator.com. [Accessed: 29th June 2014]

[4] International Data Corporation: 2014 Smartphone market share Q4 [online] available from::http://www.idc.com/prodserv/smartphone-osmarket-share.jsp. [Accessed: 20th June 2014].

[5] Allen, S., Vidal, G., Lee, L. 2010 Phonegap. Pro Smartphone Cross-Platform Development: iPhone, Blackberry, Windows Mobile and Android Development and Distribution (1:Ed) Berkely, CA, USA: .(pp21-36) Apress

[6] G. Hartmann, Stead, G. and A. DeGani. 2011 Crossplatform mobile development, Tribal, Lincoln House,

[7] Vision Mobile 2012 Cross-Platform Developer Tools: Bridging the worlds of mobile apps and the web. [Online] available from http://www.slideshare.net/andreasc/visionmobilecrossplatformdevelopertools2012 [Accessed: 21st June 2014].

[8] Ohrt, J. and Tarau, V. 2012 Cross Platform Development Tools for Smartphone Applications.
[9] Sibai, F 2008 Evaluating the Performance of Single and Multiple Core Processors with PCMARK 05 and Benchmark Analysis.

[10] Antutu Hong Kong 2012 Antutu Benchmark: "know your Android better [Online].Available from:http://www.antutu.com. [Acessed: 27th November 2014].

[11] Uti, N and Fox, R 2010 Testing the Computational Capabilities of Mobile Device Processors: Some Interesting Benchmark Results in 2010 IEEE/ACIS 9th International Conference on Computer and Information Science (ICIS), Washington, DC, USA.

[12] Aurora Softworks 2012 Aurora Softworks Home: [Online]Availablefromhttp://www.aurorasoftworks.com [Accessed 29th July 2014]

[13] Issa, J. 2011 TMAPP - Typical Mobile Applications Benchmark," in MoBS7 '11: Seventh Annual Workshop on Modeling, Benchmarking and Simulation.

[14] Bull, J, M, Smith L, A. Pottage, L. and Freeman, R. 2001 Benchmarking Java against C and Fortran for scientific applications, in Proceedings of the 2001 joint ACM-ISCOPE conference on Java Grande, 2001.

[15] Saaty, T.L. 2001 Decision making with the analytic hierarchy process, Int. J. Services Sciences, Vol. 1, No. 1

[16] Ciman, M., Gaggi, O. and Gonzo, N 2014 Cross Platform Mobile Development: A study on Apps with animations $\mathrm{ACM}$ 